ORGANISATIONAL MATTERS

\title{
The economic burden of complications during percutaneous coronary intervention
}

\author{
Kurt M Jacobson, Kirsten Hall Long, Erin K McMurtry, James M Naessens, Charanjit S Rihal
}

Qual Saf Health Care 2007;16:154-159. doi: 10.1136/qshc.2006.019331

See end of article for authors' affiliations

Correspondence to:

Charanjit S Rihal, Mayo

Clinic, 200 First Street SW,

Rochester, Minnesota, USA;

rihal@mayo.edu

Accepted 30 November 2006

\begin{abstract}
Background: Technological advances have enabled percutaneous coronary intervention (PCI) to be applied with expanding indications. However, escalating costs are of concern. This study assessed the incremental medical costs of major in-hospital procedural complications incurred by patients undergoing $\mathrm{PCl}$.

Methods: We considered all patients undergoing elective, urgent, or emergent $\mathrm{PCl}$ at Mayo Clinic Rochester between 3/1/1998-3/31/2003 in analyses. Clinical, angiographic, and outcome data were derived from the Mayo Clinic PCl Registry. In-hospital PCl complications included major adverse cardiac and cerebrovascular events (MACCE) and bleeding of clinical significance. Administrative data were used to estimate total costs in standardised, year 2004, constant-US dollars. We used generalised linear modeling to estimate costs associated with complications adjusting for baseline and procedural characteristics.

Results: 1071 (13.2\%) of patients experienced complications during hospitalisation. Patients experiencing complications were older, more likely to present with emergent $\mathrm{PCl}$, recent or prior myocardial infarction, multi-vessel disease, and comorbid conditions than patients who did not experience these events. Unadjusted total costs were, on average, $\$ 27865 \pm \$ 39424$ for complicated patient episodes compared to $\$ 12279 \pm \$ 6796$ for episodes that were complication free $(p<0.0001)$. Adjusted mean costs were $\$ 6984$ higher for complicated $\mathrm{PCl}$ compared with uncomplicated $\mathrm{PCl}$ episodes $195 \% \mathrm{Cl}$ of cost difference: $\$ 5801$, \$8168). Incremental costs associated with isolated bleeding events, MACCE, or for both bleeding and MACCE events were $\$ 5883, \$ 5086$, and $\$ 15437$, respectively $(p<0.0001)$.

Conclusions: This high-volume study highlights the significant economic burden associated with procedural complications. Resources and systems approaches to minimising clinical and economic complications in $\mathrm{PCl}$ are warranted.
\end{abstract}

$\mathrm{P}$ ercutaneous coronary intervention (PCI) is a resource intensive and commonly performed procedure in the United States today. In 2003 an estimated 1.2 million PCI procedures were performed; an increase of $326 \%$ since $1987 .{ }^{1}$ Innovations including glycoprotein IIb-IIIa inhibitors and bare metal stents have improved immediate outcomes, decreased inhospital adverse ischemic events, and allowed for rapid expansion of PCI. ${ }^{2-7}$ A more recent innovation, drug-eluting stents, may offer additional clinical benefits from a patient and societal perspective with reduced need for repeat target vessel revascularisation (TVR) over time. ${ }^{8-10}$ From a provider perspective, however, increased supply and labour costs, changes in coronary artery bypass referral patterns, as well as escalating reimbursement pressures may, in some cases, have rendered previously strong institutions insolvent. ${ }^{11}$

Some organisations have successfully reduced length of stay (LOS) and procedural costs through clinical pathway implementation and competitive bidding for high cost supplies. ${ }^{12}{ }^{13}$ Practices changes aimed at reducing in-hospital complication rates for other procedures have also been successful in reducing costs, although published economic examples in interventional cardiology are limited. ${ }^{14-20}$ To test the hypothesis that clinical complications are important determinants of the cost of providing care we assessed the incremental direct costs associated with major in-hospital procedural complications incurred by patients undergoing PCI. Increased knowledge of the economic burden associated with complications may highlight areas ripe for quality improvement and lead to enhanced financial performance.

\section{METHODS}

Study population

All patients undergoing elective, urgent, or emergent PCI at Mayo Clinic Rochester, Minnesota between March of 1998 and
March of 2003 were included in the analysis. Patient inclusion dates were chosen to reflect 5 years PCI experience during a period of relative practice stability in terms of procedural supplies and adjunctive pharmacotherapy. Cohort termination was immediately prior to the release of drug-eluting stents into practice April of 2003. We chose to exclude drug-eluting stenttreated patients given known higher supply costs and the potential for confounding of costs attributed to the treatment of procedural complications. Controlled trials to date demonstrate similar in-hospital adverse events rates with use of drug-eluting or bare metal stents adjunctive to PCI. ${ }^{8-10}$

Multiple qualifying procedures per patient during the study period were included but a repeat procedure on the same lesion (TVR) within the identified hospital episode was considered a complication of initial PCI and not a qualifying "index" PCI event. Elective, staged procedures during the same hospitalisation were excluded as atypical events $(n=212)$. We obtained Institutional Review Board approval for this study. As required by Minnesota statute, patients not granting authorisation for use of their records in research were excluded prior to data collection.

\section{Interventional procedures}

PCI was performed using standard techniques. ${ }^{21}$ Patients received oral aspirin $(325 \mathrm{mg})$ at the time of procedure. Glycoprotein IIb/IIIa inhibitors (abciximab, eptifibatide, or tirofiban) were administered as adjunctive therapy at the discretion of the operator. For patients undergoing stent

\footnotetext{
Abbreviations: $G L M$, generalised linear modelling; ICD-9, international classification of diseases, ninth revision; LOS, length of stay; MACCE, major adverse cardiac and cerebrovascular events; $\mathrm{PCl}$, percutaneous coronary intervention; TVR, target vessel revascularisation
} 
implantation, clopidogrel was given as a $300 \mathrm{mg}$ loading dose and $75 \mathrm{mg}$ daily for 4 weeks post procedure. Weight adjusted heparin was infused to maintain an activated clotting time of 200-250 seconds when used with a glycoprotein IIb/IIIa inhibitor and 250-300 seconds when used with unfractionated heparin alone. Heparin use was discontinued after the procedure. Only bare metals stents were used during the study time frame.

\section{Data sources and definitions}

All patients undergoing PCI at Mayo Clinic have been followed prospectively since 1979 according to a well-established protocol, the Mayo Clinic PCI Registry. ${ }^{22}$ This database contains baseline demographic, clinical, and angiographic data as well as information on patient outcomes during follow-up. All patients are interviewed in person or by telephone at 6 months and 12 months after PCI and yearly thereafter to assess major adverse cardiovascular events.

Angiographic characteristics and procedural success are determined and documented by the PCI operator. A blinded team of registered nurses and data coordinators collect and enter all pre- and post-procedural data including the occurrence of adverse clinical events. Blinded data adjudication is conducted as needed by an interventional cardiologist not the operator for the case in question. Ten percent of records are audited for quality assurance by the supervisor of the data coordinators. Medical records for care received for these events at Mayo Clinic and other institutions are obtained for review with the patient's written informed authorisation for release of such information.

Procedural episodes were categorised as complicated or free of complications conditional on whether the patient experienced a major adverse cardiac or cerebrovascular event (MACCE) or had bleeding of clinical significance during hospitalisation. MACCE events included: death, myocardial infarction, emergent coronary artery bypass surgery, target vessel revascularisation, and stroke. Myocardial infarction was defined as any two of the following criteria: an episode of prolonged angina lasting $\geqslant 20$ minutes, a rise in the serum creatine kinase (CK)-MB isoenzyme greater than two-fold normal, or ST-segment/T-wave changes or new Q-waves on serial electrocardiograms indicative of myocardial damage. Bleeding events of clinical significance included blood loss requiring transfusion, aneurysm, hematoma, central nervous system bleed, gastrointestinal bleed, and retroperitoneal bleed.

Economic analyses were conducted from the provider perspective and focused on direct costs of care associated with hospital and physician services during inpatient stay. Administrative data sources were used to track medical resource utilisation and related expenditures for these PCI episodes of interest. Utilisation was valued using standard methods by grouping services into the Medicare Part A and B classification: Part A billed charges were adjusted using hospital cost-to-charge ratios at the departmental level and wage indexes. ${ }^{23}$ Costs associated with Part B physician services were proxied based on Medicare reimbursement rates. Direct hospital (technical costs) were "fully loaded" and included costs associated with overhead. Accounting practices remained unchanged during the study duration. All cost presented have been adjusted to reflect 2004 constant US dollars.

\section{Statistical analysis}

We report continuous variables as mean \pm standard deviation and categorical variables as frequencies and percentages. Patient characteristics and observed economic outcomes were compared between groups using t-tests and chi-square tests, as appropriate. Observed complication rates are reported as percentage of PCI episodes observed with complication of interest out of the entire sample of PCI hospitalisations. Multivariate regression techniques were used to evaluate the independent effect of complications on costs adjusting for demographic, clinical, angiographic, and procedural characteristics.

Demographic variables of interest included age and gender. Clinical characteristics included clinical presentation (elective or emergent PCI), recent or prior history of myocardial infarction, prior PCI or coronary artery bypass graft surgery, pre-procedural shock, body mass index, and history of smoking (current or former smoker). Co-morbid conditions were also considered in analyses such as presence of angina, diabetes (treated with medication or diet), hypertension (blood pressure greater than 140/90 mmHg treated with medication), congestive heart failure, peripheral vascular disease, history of cerebrovascular accident, stroke, or a transient ischemic attack, chronic renal failure, peptic ulcer disease, cancer, and the presence of a prophylactic intra-aortic balloon pump at baseline. Additional covariates included procedural characteristics such as the date of the procedure, presence of multi-vessel disease, complexity of lesion (B2 or C type), thrombus containing lesion, calcium in any stenosis, number of vessels and segments treated, number of stents placed, glycoprotein IIb/IIIa inhibitor usage, vein graft intervention, and whether PCI was performed on the proximal left anterior descending coronary artery. Finally, for more complete risk adjustment, cost prediction models also included baseline clinical and economic summary severity measures (Expected Mortality Score, Overall Resource Demand Scale, and LOS Scale) shown to predict mortality and economic outcomes in a development database containing approximately 15 million patient records. ${ }^{24}$

Patient level estimated severity measures were obtained by using the listed international classification of diseases, ninth revision, clinical modification (ICD-9-CM) diagnosis codes for pre-existing conditions, age, sex, and admission status (noted in administrative data) processed through Disease Staging software. ${ }^{24}$ Disease Staging software assigns a disease category and stage of disease to every diagnosis code on the patient inpatient record. Patient level combinations of disease and severity correspond to the pre-determined scales shown to predict the outcomes of interest. Resource Demand Scale, for example, is a measure of expected resource consumption conditional on known co-morbidities and severity of illness at baseline scaled to average 100 across all patients in the development database. An estimated Resource Demand Scale of 125, therefore, implies $25 \%$ higher expected resource consumption (charges) compared with the average of predicted charges taken across all patients in the database. Further details on this Disease Staging process, development of the predictive scales, as well as a bibliography of research involving Disease Staging are available online (http://www.hcup-us.ahrq.gov/db/nation/nis/ Disease\%20Staging\%20V5.22\%20Reference\%20Guide.pdf).

Models were developed separately to assess incremental costs associated with experiencing at least one of the selected complications, MACCE only events, only bleeding events, and MACCE and bleeding events. Generalised linear modelling (GLM) was used to assess costs to account for the non-negative and typically skewed nature of economic outcomes. ${ }^{25}$ Cost models assumed a logarithmic link function and an inverse Gaussian distribution function. Choice of family distribution was determined empirically based on the modified Park test recommended by Manning and Mullahy. ${ }^{26}$ Although the percentage of missing values per covariate was small (no greater than $10 \%$ ), data were unavailable on at least one covariate in $30.9 \%$ of the PCI episodes. We considered alternative methods for handling these missing data (case 
Table 1 Baseline and procedural characteristics of $\mathrm{PCl}$ patients by complication status*

\begin{tabular}{|c|c|c|c|}
\hline Variable & $\begin{array}{l}\text { Uncomplicated PCI } \\
\text { ( } \mathrm{n}=7038)\end{array}$ & $\begin{array}{l}\text { Complicated } \mathrm{PCl} \\
(\mathrm{n}=1071)\end{array}$ & p Value \\
\hline Age, years & $65.8 \pm 11.9$ & $71.0 \pm 11.7$ & $<0.001$ \\
\hline Male gender (No./\%) & $5089(72)$ & $628(59)$ & $<0.001$ \\
\hline Body Mass Index & $29.7 \pm 5.6$ & $28.7 \pm 5.7$ & $<0.001$ \\
\hline Unstable angina & $4353(62)$ & $583(54)$ & $<0.001$ \\
\hline MI 1-7 days before procedure & $975(14)$ & $196(18)$ & $<0.001$ \\
\hline Pre-procedural shock & $145(2)$ & $167(16)$ & $<0.001$ \\
\hline MI day of procedure or $\leqslant 24$ hours & $1017(15)$ & $296(28)$ & $<0.001$ \\
\hline Urgency of $\mathrm{PCl}$ & & & $<0.001$ \\
\hline Elective & $2486(35)$ & $252(24)$ & \\
\hline Urgent & 3422 (49) & $460(43)$ & \\
\hline Emergency & $1130(16)$ & $359(34)$ & \\
\hline $\mathrm{CHF}$ on presentation & $599(9)$ & $231(22)$ & $<0.001$ \\
\hline Diabetes & $1696(24)$ & $276(26)$ & 0.23 \\
\hline Hypertension & $4665(66)$ & $753(70)$ & 0.004 \\
\hline Peripheral vascular disease & $681(10)$ & $164(15)$ & $<0.001$ \\
\hline Moderate/severe renal disease§ & $162(2)$ & $85(8)$ & $<0.001$ \\
\hline Current smoker & $1258(18)$ & $165(67)$ & $<0.001$ \\
\hline Prior Ml & $3781(54)$ & $721(67)$ & $<0.001$ \\
\hline Prior $\mathrm{PCl}$ & 2387 (34) & $296(28)$ & $<0.001$ \\
\hline Prior CABG & $1536(22)$ & $243(23)$ & 0.52 \\
\hline$E F \leqslant 40$ & $708(10)$ & $162(15)$ & $<0.001$ \\
\hline Number diseased vessels (70/50 definition)\# & & & $<0.001$ \\
\hline 0 & $156(2)$ & $12(1)$ & \\
\hline 1 & $1957(28)$ & $230(22)$ & \\
\hline 2 & $2561(36)$ & $374(35)$ & \\
\hline 3 & $1892(27)$ & $408(38)$ & \\
\hline B2 or $C$ type lesion & 4959 (71) & $794(74)$ & $<0.001$ \\
\hline Thrombus in lesion & $1859(26)$ & $463(43)$ & $<0.001$ \\
\hline Calcified artery & $2052(29)$ & 414 (39) & $<0.001$ \\
\hline Eccentric lesion & 4807 (68) & $718(67)$ & 0.09 \\
\hline Bifurcation lesion & $815(12)$ & $152(14)$ & 0.01 \\
\hline Ulcerated lesion & $572(8)$ & 118 (11) & $<0.001$ \\
\hline Ostial lesion & $1090(16)$ & $202(19)$ & 0.01 \\
\hline Moderate or severe bend in lesion & $1938(28)$ & $372(35)$ & $<0.001$ \\
\hline Major side-branches in lesion & $1249(18)$ & $244(23)$ & $<0.001$ \\
\hline Number of segments treated & $1.5 \pm 0.7$ & $1.7 \pm 0.9$ & $<0.001$ \\
\hline Total number of vessels treated ${ }^{* *}$ & $1.2 \pm 0.4$ & $1.2 \pm 0.4$ & $<0.001$ \\
\hline Glycoprotein Ilb/Illa inhibitor use & $3872(55)$ & $695(65)$ & $<0.001$ \\
\hline Total number of stents placed & $1.4 \pm 1.0$ & $1.6 \pm 1.3$ & $<0.001$ \\
\hline \multicolumn{4}{|c|}{$\begin{array}{l}\text { *For variables with missing data, the percentages reflect the percent of those with data available. } \\
\text { §Moderate/severe renal disease defined as serum creatinine }>3 \mathrm{mg} / \mathrm{dL} \text {. } \\
\text { \#Number of diseased vessels with at least one vessel having } \geqslant 70 \% \text { stenosis and subsequent vessels with at least } \geqslant 50 \% \\
\text { stenosis; the left main and left anterior descending vessels were counted as one vessel. } \\
\text { **Numbers in table have been rounded to the nearest tenth decimal place. Observed rates are } 1.16 \pm 0.40 \text { and } \\
1.21 \pm 0.44 \text { for uncomplicated and complicated } \mathrm{PCl} \text {, respectively. } \\
\text { CABG, coronary artery bypass graft; CHF, congestive heart failure; EF, ejection fraction; } \mathrm{Ml} \text {, myocardial infarction; } \mathrm{PCl} \text {, } \\
\text { percutaneous coronary intervention. }\end{array}$} \\
\hline
\end{tabular}

deletion, mean imputation, as well as more sophisticated multiple imputation methods), however results did not differ substantially by approach used. For simplicity and brevity, we present only results obtained using the mean imputation method. ${ }^{27}$ All statistical tests were two-sided, and p values less than 0.05 were considered significant. SAS version 9.1 (SAS Institute Inc., Cary, NC, USA) was used in the analyses.

\section{RESULTS}

\section{Patient characteristics}

A total of 8109 PCIs were performed on 7027 patients during the study duration; 1071 (13.2\%) of the identified 8109 PCIs were associated with at least one complication. Table 1 presents the baseline and procedural characteristics of the study population according to whether the patient experienced at least one of the selected complications during hospitalisation. "Complicated" patients were older (71 vs 66 years of age), more likely female $(41 \%$ vs $28 \%)$, more likely to present with emergent PCI ( $34 \%$ vs 16\%), pre-procedural shock ( $16 \%$ vs $2 \%$ ), had a higher number of recent or prior myocardial infarctions ( $28 \%$ vs 15\%; myocardial infarction within 24 hours of PCI), more likely to have multi-vessel disease ( $75 \%$ vs $65 \%$ ), along with other high-risk angiographic characteristics (such as B2/C type lesions, thrombus containing lesion, calcium in any stenosis, ulcer or moderate or severe angulated bends at treatment sites). With the exception of diabetes, all co-morbid conditions of interest (for example, hypertension, congestive heart failure, renal disease, and cancer) were more prevalent among patients who experienced complications compared with patients who were free of these adverse events. While both groups were as likely to receive an intracoronary stent $(86 \%)$, complicated procedures had more stents placed per procedure (1.6 vs 1.4), more liberal glycoprotein IIb/IIIa inhibitor usage ( $65 \%$ vs $55 \%$ ), as well as had more vessels and target segments treated.

\section{Observed complication rates}

Table 2 provides a breakdown of observed adverse events by complication category. MACCE events occurred in $7.1 \%$ of PCI episodes. Myocardial infarction was the most common MACCE to occur among the complicated episodes followed by death (5.2\% and $1.6 \%$, respectively). The composite of bleeding complications occurred in $7.9 \%$ of PCIs with $6.0 \%$ requiring transfusion and $2.5 \%$ developing an access site hematoma. 


\begin{tabular}{ll} 
Table 2 Observed in-hospital adverse events by \\
complication category \\
\hline Complication & $\mathbf{n}(\%)$ \\
\hline Any complication & $1071(13.2)$ \\
MACCE complications & $577(7.1)$ \\
Death & $130(1.6)$ \\
Myocardial infarction & $419(5.2)$ \\
Emergent CABG & $35(0.4)$ \\
Target vessel revascularisation & $33(0.4)$ \\
Stroke & $35(0.4)$ \\
Bleeding complications & $641(7.9)$ \\
Blood loss requiring transfusion & $484(6.0)$ \\
Hematoma & $203(2.5)$ \\
Aneurysm & $62(0.8)$ \\
Central nervous system bleed & $0(0)$ \\
Gastrointestinal bleed & $76(0.9)$ \\
Retriperitoneal bleed & $23(0.3)$ \\
Bleeding only & $494(6.1)$ \\
MACCE only & $430(5.3)$ \\
MACCE and bleeding & $147(1.8)$ \\
\hline CABG, coronary artery bypass graft; PCl, percutaneous coronary \\
intervention; MACCE, major adverse cardiovascular and cerebrovascular \\
events
\end{tabular}

Simultaneous occurrence of both MACCE and bleeding events within a procedural episode were rare, occurring in less than $2 \%$ of PCI hospitalisations.

\section{Observed economic outcomes}

Unadjusted inpatient costs and length of stay by selected complication are shown in table 3. Mean observed total costs per episode were markedly higher for patients who experienced a complication compared with those who were complication free (\$27 865 vs $\$ 12279 ; 95 \%$ CI of cost difference: $\$ 14579$, $\$ 16593)$. Length of stay was also markedly longer among complicated PCI episodes with an observed mean difference of 4.5 days between complicated and uncomplicated PCIs (6.4 days vs 1.9 days; $p<0.0001$, respectively). Both MAACEonly events and bleeding-only events significantly contributed to prolonged length of stays and increased costs of care (unadjusted incremental cost differences of $\$ 9096$ and $\$ 13$ 092, on average, respectively, compared to uncomplicated episodes). Multiple complications were associated with the highest in-hospital costs. Episodes complicated by both MACCE and bleeding events cost, on average, nearly $\$ 43000$ more per
PCI hospitalisation (\$55 230 vs $\$ 12279 ; 95 \%$ CI of cost difference: \$40 593, \$45 310). Direct medical costs for all PCI episodes of interest totalled $\$ 116260325 ; 25.7 \%$ of which (\$29843 246) was incurred by the $13.2 \%$ of procedural episodes with complications.

\section{Adjusted incremental costs}

In all adjusted analyses, procedural complications were strongly associated with inpatient costs of care. Table 4 presents the estimated incremental costs associated with treatment of these selected complications with adjustment for differences in patient demographic, clinical, and procedural characteristics. A large and significant cost differential between complicated and uncomplicated procedures persisted even after adjustment for other factors. For instance, adjusted mean total costs were estimated to be $\$ 6984$ higher for hospitalisations where the patient experienced at least one of the selected complications compared with complication free hospitalisations (95\% CI of cost difference: \$5801, \$8168). Similarly, incremental inpatient costs associated with only bleeding events, only MACCE, or for episodes where the patient experiencing both bleeding and MACCE events were \$5883, \$5086, and \$15 437, respectively $(\mathrm{p}<0.0001)$.

\section{DISCUSSION}

Our objective was to assess the incremental costs of treating major in-hospital procedural complications among patients undergoing PCI in recent clinical practice. Observed and adjusted results suggest that resource utilisation and treatment costs are substantially greater during PCI hospitalisation when complications occur. On average, complications more than double the costs of uncomplicated PCI. Adjusted excess costs associated with procedural complications ranged, on average, from a low of $\$ 5086$ for episodes with MACCE events to over $\$ 15000$ for episodes complicated by MACCE and bleeding events. Bleeding complications alone were observed to be major contributors to cost, with mean observed costs of \$25371 compared to observed costs of $\$ 12279$, on average, for uncomplicated procedural episodes. Interestingly, incremental costs associated with bleeding slightly surpassed those associated with ischemic events (adjusted mean incremental costs of $\$ 5883$ and $\$ 5086$, respectively). This is unlikely a reflection of increased bleeding complications at our facility as previous studies have demonstrated similar rates of bleeding

Table 3 Observed inpatient costs and length of stay by selected complication

\begin{tabular}{|c|c|c|}
\hline & \multicolumn{2}{|l|}{ Total costs (\$) } \\
\hline & Mean (median) $\pm S D$ & Difference $(95 \% \mathrm{Cl})$ \\
\hline $\begin{array}{l}\text { All PCl episodes } \\
\text { Uncomplicated PCI } \\
\text { Any complication } \\
\text { Bleeding only } \\
\text { MACCE only } \\
\text { MACCE and bleeding }\end{array}$ & $\begin{array}{l}14337(11380) \pm 16524 \\
12279(10776) \pm 6796 \\
27865(18462) \pm 39424 \\
25371(18234) \pm 21193 \\
21375(16366) \pm 17954 \\
55230(30714) \pm 89598\end{array}$ & $\begin{array}{l}- \\
- \\
15586(14579,16593) \\
13092(12315,13869) \\
9096(8329,9864) \\
42952(40593,45310)\end{array}$ \\
\hline \multirow{2}{*}{ MACCE and bleeding } & \multicolumn{2}{|l|}{ Length of stay (days) } \\
\hline & Mean (median) $\pm S D$ & Difference $(95 \% \mathrm{Cl})$ \\
\hline $\begin{array}{l}\text { All PCl episodes } \\
\text { Uncomplicated PCI } \\
\text { Any complication } \\
\text { Bleeding only } \\
\text { MACCE only } \\
\text { MACCE and bleeding }\end{array}$ & $\begin{array}{l}2.5(1.0) \pm 4.7 \\
1.9(1.0) \pm 2.2 \\
6.4(4.0) \pm 11.0 \\
6.2(4.0) \pm 7.0 \\
4.1(3.0) \pm 4.3 \\
13.5(7.0) \pm 24.7\end{array}$ & $\begin{array}{l}- \\
- \\
4.5(4.2,4.8) \\
4.4(4.1,4.6) \\
2.2(2.0,2.5) \\
11.6(10.9,12.3)\end{array}$ \\
\hline
\end{tabular}


complications to ours $(7.9 \%)$, with rates ranging from $2.2 \%$ to $14 \%{ }^{28-33}$ Ischemic event rates are also similar. ${ }^{6}{ }^{29} 34$

\section{Comparison to previous work}

While much clinical research to date has focused on the incidence of PCI procedural complications, economic research on the associated cost burden is just emerging. Nikolsky et $\mathrm{al}^{35}$ recently assessed the economic impact of in-hospital acquired thrombocytopenia in patients undergoing primary PCI for acute myocardial infarction. Findings suggested that patients who developed thrombocytopenia versus those who did not had higher in-hospital rates of major hemorrhagic complications, greater blood transfusion requirements, incurred longer hospital stays, and increased inpatient costs (median \$14 466 vs $\$ 11629, \mathrm{p}=0.001$ ).

Kugelmass et $a l^{36}$ also noted significantly higher resource use among Medicare beneficiaries associated with acute PCI complications (major adverse ischemic events, vascular complications, acute renal failure, septicemia, and adult respiratory distress syndrome). Estimated incremental costs associated with complications ranged from a high of $\$ 33030$ for septicemia patients to a low estimate of $\$ 4278$ for patients developing vascular complications. Key study limitations noted by the authors include a selected Medicare population and reliance on administrative data (ICD-9 billing codes) for identification of complications and patient characteristics.

In contrast, our study focused on a large unselected population and had access to detailed clinical registry data including the occurrence of adverse clinical events (with blinded data adjudication by clinicians as needed). This wealth of patient registry data also allowed us to control for a number of angiographic and procedural characteristics (for example stent usage) that potentially confound the effect of complications on costs. These methodological differences likely contribute to our varying nominal results. In general, however, our study results confirm those reported by Kugelmass et $a l^{36}$ highlighting that complications contribute significantly to inpatient costs of care. Furthermore, both studies suggest that the economic impact of vascular complications may be similar to incremental costs associated with the treatment of some major ischemic events (such as death) and that heightened clinical awareness towards reduced bleeding event rates is clearly warranted.

While use of improved stents and antithrombotic strategies has reduced the incidence of ischemic events following PCI, access-site bleeding has now evolved as one of the more common procedural complications. ${ }^{2-10} 29$ Bleeding after PCI comprises a wide range of possible events, from a minor access-site hematoma or need for blood transfusion, to a fatal intracranial hemorrhage. The need for blood transfusion was previously found to be the strongest post-procedure predictor of LOS. $^{37}$

Certain patient characteristics appear to be associated with higher risks of bleeding. Kinnaird, et al ${ }^{38}$ discovered that age

Table 4 Adjusted mean incremental medical costs associated with select complications

\begin{tabular}{ll}
\hline Complication & Incremental cost* $(95 \% \mathrm{CI})$ \\
\hline Any complication & $\$ 6,984(\$ 5801, \$ 8168)$ \\
Bleeding only & $\$ 5883(\$ 5498, \$ 6269)$ \\
MACCE only & $\$ 5086(\$ 4739, \$ 5433)$ \\
MACCE and bleeding & $\$ 15437(\$ 14010, \$ 16864)$ \\
\hline
\end{tabular}

*Separate GLM models assessing costs were estimated for each of the selected complications controlling for patient characteristics.

$\mathrm{Cl}$, confidence interval; GLM, generalised linear modeling; $M A C C E$, major adverse cardiovascular and cerebrovascular events. greater than 80 years and chronic renal insufficiency were strongly associated with bleeding complications. Female gender and prolonged PCI times were also independently associated with increased bleeding risk. ${ }^{39}$ Using these identifiable characteristics to create an integer risk score for bleeding complications, not unlike that done for ischemic complications, may assist in establishing patients at greatest risk for these events. ${ }^{40}$ Continued investigation into ways of reducing bleeding complications such as changes in peri-procedural anticoagulation, closure-mediated devices, or procedural technique (that is radial versus femoral access) is warranted. ${ }^{20} 3441-43$ Results presented here suggest the interests of patients, hospital administrators, and physicians are perfectly aligned with respect to reduction of procedural complication rates; successful quality improvement will likely lead to enhanced expense management.

\section{Limitations}

Although we had access to both comprehensive clinical and administrative data, it is possible we failed to control for all factors likely to influence procedural costs biasing our incremental cost estimates. Our study also reflects the experience of a single, high-volume referral centre. Patients and results may differ in other centres and practice settings.

\section{CONCLUSIONS}

Although relatively infrequent events, the economic burden associated with acute procedural complications is significant. Greater than $25 \%$ of the total costs associated with PCI in our case were attributed to complicated procedural episodes. Yet in only $13 \%$ of episodes did complications occur. In today's fiscally restricted healthcare environment, identifying methods of costcontainment while preserving or even improving clinical outcomes has become increasingly essential to provider financial stability. Results presented here suggest that interventions to reduce the risk of adverse events will likely enhance financial as well as clinical performance. Resources and systems approaches to minimising clinical and economic complications in PCI are warranted.

\section{ACKNOWLEDGEMENTS}

The authors thank Ms Dawn Finnie for administrative assistance.

\section{Authors' affiliations}

Kurt M Jacobson, Division of Internal Medicine, Mayo Clinic College of Medicine, Mayo Clinic, Rochester, Minnesota, USA

Kirsten Hall Long, Erin K McMurtry, James M Naessens, Division of Health Care Policy \& Research, Mayo Clinic College of Medicine, Mayo Clinic, Rochester, Minnesota, USA

Charanjit S Rihal, Division of Cardiovascular Diseases, Mayo Clinic College of Medicine, Mayo Clinic, Rochester, Minnesota, USA

Funding: Mayo Foundation for Medical Education and Research.

Competing interest: None.

Previous presentation: Presented as a poster at the International Society for Pharmacoeconomics and Outcomes Research $8^{\text {th }}$ Annual European Congress; November 7, 2005; Florence, Italy. Additional oral presentation occurred at the Inaugural Conference of the American Society of Health Economists; June 6, 2006; Madison, Wisconsin, USA.

\section{REFERENCES}

1 American Heart Association. Heart Disease and Stroke Statistics-2006 Update. Dallas, Texas: American Heart Association, 2006, Available at http:// www.americanheart.org/presenter.jhtml? identifier $=1928$ (accessed 13 February 2006).

2 The EPISTENT Investigators. Evaluation of Platelet Ilb/Illa Inhibitor for Stenting. Randomized placebo-controlled and balloon angioplasty-controlled trial to assess safety of coronary stenting with use of platelet glycoprotein-llb/Illa blockade. Lancet 1998;352:87-92. 
3 Lincoff AM, Califf RM, Moliterno DJ, et al. Complementary clinical benefits of coronary-artery stenting and blockade of platelet glycoprotein Illb/Illa receptors. Evaluation of Platelet Ilb/Illa Inhibition in Stenting Investigators. N Engl J Med 1999;341:319-27.

4 Montalescot G, Barragan P, Wittenberg O, et al. Platelet glycoprotein Ilb/Illa inhibition with coronary stenting for acute myocardial infarction. N Engl J Med 2001;344:1895-903.

5 Stone GW, Grines CL, Cox DA, et al. Comparison of angioplasty with stenting, with or without abciximab, in acute myocardial infarction. N Engl J Med 2002:346:957-66.

6 ESPRIT Investigators. Enhanced Suppression of the Platelet Ilb/Illa Receptor with Integrilin Therapy. Novel dosing regimen of eptifibatide in planned coronary stent implantation (ESPRIT): a randomized, placebo-controlled trial, Lancet 2000;356:2037-44

7 O'Shea JC, Hafley GE, Greenberg S, et al. Platelet glycoprotein Ilb/Illa integrin blockade with eptifibatide in coronary stent intervention: the ESPRIT trial: a randomized controlled trial. JAMA 2001;285:2468-73.

8 Morice MC, Serruys PW, Sousa JE, et al. A Randomized Comparison of a Sirolimus-Eluting Stent with a Standard Stent for Coronary Revascularization. N Engl J M 2002;346:1773-1780.

9 Moses JW, Leon MB, Popma JJ, et al. Sirolimus-eluting stents versus standard stents in patients with stenosis in a native coronary artery. N Engl J Med 2003;349:1315-1323.

10 Stone GW, Ellis SG, Cox DA, et al. A polymer-based, paclitaxel-eluting stent in patients with coronary artery disease. N Engl J Med 2004;350:221-231.

11 Kong DF, Eisenstein EL, Sketch MH, et al. Economic impact of drug-eluting stents on hospital systems: a disease-state model. Am Heart J 2004; 147:449-456.

12 Eagle KA, Knight BP, Moscucci M, et al. Competitive bidding for interventional cardiology supplies: lessons learned during round 2. Am J Manag Care 2002;8:384-388

13 Moscucci M, Muller DW, Watts CM, et al. Reducing costs and improving outcomes of percutaneous coronary interventions. Am J Manag Care 2003:9:365-372.

14 Ferguson TB Jr, Peterson ED, Coombs LP, et al. Use of continuous quality improvement to increase use of process measures in patients undergoing coronary artery bypass graft surgery: a randomized controlled trial. JAMA 2003:290:49-56.

15 Cheah J. Clinical pathways--an evaluation of its impact on the quality of care in an acute care general hospital in Singapore. Singapore Med J 2000;41:335-346.

16 Malenka DJ, O'Connor GT. The Northern New England Cardiovascular Disease Study Group: a regional collaborative effort for continuous quality improvement in cardiovascular disease. Jt Comm J Qual Improv 1998;24:594-600.

17 Hashimoto H, Bohmer RM, Harrell LC, et al. Continuous quality improvement decreases length of stay and adverse events: a case study in an interventional cardiology program. Am J Manag Care 1997;3:1141-1150.

18 Eagle KA, Moscucci M, Kline-Rogers E, et al. Evaluating and improving the delivery of heart care: the University of Michigan experience. Am J Manag Care 1998;4:1300-1309

19 Senter DR, Nathan S, Gupta A, et al. Clinical and economic outcomes of embolic complications and strategies for distal embolic protection during percutaneous coronary intervention in saphenous vein grafts. J Invasive Cardiol 2006; 18:49-53.

20 Cohen DJ, Lincoff AM, Lavelle TA, et al. Economic evaluation of bivalirudin with provisional glycoprotein Ilb/Illa inhibition versus heparin with routine glycoprotein Ilb/Illa Inhibition for Percutaneous Coronary Intervention: Results from the REPLACE-2 trial. J Am Coll Cardiol 2004;44:1792-1800.

21 Holmes DR Jr, Vlietstra RE. Percutaneous transluminal coronary angioplasty: current status and future trends. Mayo Clin Proc 1986;61:865-876.

22 Hasdai D, Garratt KN, Grill DE, et al. Effect of smoking status on the long-term outcome after successful percutaneous coronary revascularization. N Engl J Med 1997:336:755-761.

23 Cohen DJ, Breall JA, Ho K, et al. Economics of elective coronary revascularization: comparison of costs and charges for conventional angioplasty, directional atherectomy, stenting, and bypass surgery. J Am Coll Cardio 1993;22:1052-1059.

24 The MEDSTAT Group, Inc. Medstat Disease Staging ${ }^{\text {TM }}$ Software Version 5.22. Reference guide. 2004. Available online at, http://www.hcup-us.ahrq.gov/db/ nation/nis/Disease\%20Staging\%20V5.22\%20Reference\%20Guide.pdf, Accessed November 17, 2006.

25 Barber J, Thompson S. Multiple regression of cost data: use of generalised linear models. J Health Serv Res \& Policy 2004;9:197-204.

26 Manning WG, Mullahy J. Estimating log models: to transform or not to transform? J Health Econ 2001;20:461-494.

27 Manca A, Palmer S. Handling missing data in patient-level cost-effectiveness analysis alongside randomized clinical trials. Appl Health Econ Health Policy 2005:4:65-75.

28 Weintraub WS, Mahoney EM, Ghazzal ZMB, et al. Trends in outcome and costs of coronary intervention in the 1990s. Am J Cardio 2001;88:497-503.

29 Batchelor WB, Anstrom KJ, Muhlbaier LH, et al. Contemporary outcome trends in the elderly undergoing percutaneous coronary interventions: results in 7,472 octogenarians. National Cardiovascular Network Collaboration. J Am Coll Cardiol 2000;36:723-730.

30 Cote AV, Berger PB, Holmes DR Jr, et al. Hemorrhagic and vascular complications after percutaneous coronary intervention with adjunctive abciximab. Mayo Clin Proc 2001;76:890-896.

31 Rabah M, Mason D, Muller DW, et al. Heparin after percutaneous intervention (HAPI): A prospective multicenter randomized trial of three heparin regimens after successful coronary intervention. JAMA 1999;34:461-467.

32 Laver MA, Karweit JA, Cascade EF, et al. Practice patterns and outcomes of percutaneous coronary interventions in the United States: 1995 to 1997. Am J Cardiol 2002;89:924-929.

33 Friedman HZ, Cragg DR, Glazier SM, et al. Randomized prospective evaluation of prolonged versus abbreviated intravenous heparin therapy after coronary angioplasty. J Am Coll Cardiol 1994;24:1214-1219.

34 Lincoff AM, Bittl JA, Harrington RA, et al. Bivalirudin and provisional glycoprotein IIB/Illa blockade compared with heparin and planned glycoprotein Ilb/llla blockade during percutaneous coronary intervention: REPLACE-2 randomized trial. JAMA 2003;289:853-862.

35 Nikolsky $E$, Sadeghi $M$, Effron MB, et al. Impact of in-hospital acquired thrombocytopenia in patients undergoing primary angioplasty for acute myocardial infarction. Am J Cardiol 2005;96:474-481.

36 Kugelmass AD, Cohen DJ, Brown PB, et al. Hospital resources consumed in treating complications associated with percutaneous coronary interventions. Am J Cardiol 2006;97:322-327.

37 Aronow HD, Peyser PA, Eagle KA, et al. Predictors of length of stay after coronary stenting. Am Heart J 2001;142:799-805.

38 Kinnaird TD, Stabile E, Mintz GS, et al. Incidence, predictors and prognostic implications of bleeding and blood transfusion following percutaneous interventions. Am J Cardiol 2003;92:930-935.

39 Cohen DJ, Becker ER, Culler SD, et al. Impact of patient characteristics, complications, and facility volume on the costs and time of cardiac catheterization and coronary angioplasty in 70 catheterization laboratories. Am J Cardiol 2000;86:595-601.

40 Singh M, Lennon RJ, Holmes DR, et al. Correlates of procedural complications and a simple integer risk score for percutaneous coronary intervention. J Am Coll Cardiol 2002;40:387-393.

41 Chew DP, Lincoff AM, Gurm H, et al. Bivalirudin versus heparin and glycoprotein $\mathrm{llb} / \mathrm{llla}$ inhibition among patients with renal impairment undergoing percutaneous coronary intervention: A sub analysis of the REPLACE- 2 trial. Am J Cardiol 2005;95:581-585.

42 Keeley EC, Boura JA, Grines CL. Comparison of primary and facilitated percutaneous coronary interventions for ST-elevation myocardial infarction: quantitative review of randomised trials. Lancet 2006;367:579-588.

43 Cooper CJ, El-Shiekh RA, Cohen DJ, et al. Effect of transradial access on quality of life and cost of cardiac catheterization: A randomized comparison. Am Heart $J$ 1999; 138:430-436. 